\title{
Temperature and Humidity Controlling System for Baby Incubator
}

\author{
Abdul Latif ${ }^{1}$, Hendro Agus Widodo ${ }^{2}$, Rachmad Andri Atmoko ${ }^{3}$, Thanh Nguyen Phong ${ }^{4}$, Elsayed T.Helmy ${ }^{5}$ \\ ${ }^{1}$ Universitas Islam Sultan Agung, Semarang, Indonesia \\ ${ }^{2}$ Politeknik Perkapalan Negeri Surabaya, Surabaya, Indonesia \\ ${ }^{3}$ School of Mechanical and Electrical Engineering, Guilin University of Electronic Technology, China \\ ${ }^{4}$ Director, Department of Project Management, Ho Chi MinhCity Open University, Vietnam \\ ${ }^{5}$ National Institute of oceanography and fisheries, Alexandria \\ 4bdullatif.u.m.y@gmail.com, hendro.aw@ppns.ac.id, mokoraden@hotmail.com, phong.nt@ou.edu.vn, stalaat41@gmail.com
}

\begin{abstract}
Baby incubator is very important to keep the newborn's body temperature especially for premature babies. The research aimed to design a baby incubator with controlled temperature and humidity. The incubator is designed to have a length of $60 \mathrm{~cm}$, a width of $40 \mathrm{~cm}$, and a height of $30 \mathrm{~cm}$. System of baby incubator will automatically turn on or turn off the fan and or heating in accordance with the normal range of temperature and humidity in the incubator. The normal limits of temperature used is $33^{\circ} \mathrm{C}$ to $35^{\circ} \mathrm{C}$. While the normal limits of air humidity in the incubator used is between $40 \%$ and $60 \%$. Data acquisition system consists of temperature and humidity sensor, microcontroller ATmega8535, fan, heater, and LCD. LCD is used to display the results of measurements of temperature and humidity. Heater is used to regulate the temperature in the incubator. While fan is used to regulate the humidity in the incubator. Test results show that the heater will turn on if the temperature is below the limits of $33^{\circ} \mathrm{C}$. While the fan will turn on if the humidity is above $60 \%$.
\end{abstract}

Keywords - temperature sensor, humidity sensor, baby incubator, microcontroller

\section{INTRODUCTION}

Incubator is needed to provide warmth for premature babies. Premature babies are at risk of experiencing hypothermia (low body temperature) because in premature babies the condition of the fat tissue under the skin is lacking or still thin. Incubators are also useful to minimize the risk of premature baby contact with people and the environment that has the potential to transmit the disease because in premature babies the function of the organ is still not perfect. The temperature of the baby incubator is maintained within normal limits around $33^{\circ} \mathrm{C}$ to $35^{\circ} \mathrm{C}$. In addition, the relative humidity of $40 \%$ to $60 \%$ also needs to be maintained to help the stability of the baby's body temperature. The design of the baby incubator is expected in the future to be utilized by those who need baby incubator facilities. Hiring a baby incubator at a hospital can reach 1.5 million per day and the average baby needs that treatment for one week. You can imagine how the cost burden is very burdensome parents of babies who have little financial.

Several previous researchers have conducted research on temperature and humidity control. The Design and Implementation of Smart Control Systems for Green Buildings was researched by Gao [1]. The Fuzzy Logic Control of Humidity and Temperature Simultaneously in
Neonatal Incubators was studied by Ili [2]. The development of a modular intelligent farming system was researched by Azlin [3]. PID Temperature and Humidity Control in Granary Based on Enhanced Genetic Algorithm was investigated by Peng [4]. The control of temperature and humidity decoupling for the enthalpy difference laboratory was investigated by $\mathrm{Li}$ [5]. A comparison between fuzzy self-tuning PID and classical PID controller for greenhouse systems was investigated by Gouadria [6]. Excess Hydrogen Ratio Control PEM Fuel Cell System Ejector Based Hydrogen Recirculation was investigated by Qin [7]. The energy efficiency control strategy for building-oriented dehumidification systems was investigated by $\mathrm{Wu}[8]$. The microclimate closed cage control design for broiler strains was investigated by Wicaksono [9]. Climate Room Intelligent System for Water Supply Based on Feedforward PID researched by Zheng [10]

Cryogenic Dew and Frost Point Hygrometer experiments for Upper Air Reading were investigated by [11]. The control of agricultural greenhouse climate by using the PID selftuning fuzzy logic approach was studied by Heidari [12]. The Combined Temperature and Humidity Control Method in Museum Cabinets was investigated by Shuang [13]. The design and implementation of a constant humidity control system was investigated by $\mathrm{Wu}$ [14]. Control of nonlinear, complex and black box greenhouse systems by reinforcement learning was investigated by Ban [15]. The double-parameter double decoupling PID algorithm for the pig farming system was investigated by Tu [16]. The development of PID Control Law for ON / OFF Actuators with Operating Signal Saturation was investigated by Mama [17]. A self-tuning adaptive PID controller applied to the agro-food industry was investigated by Figueroa [18].

Low Cost Micro Predictive Mean Vote (PMV) Sensor and Its Application for Intelligent Personal Ventilation Systems was investigated by Izhar [19]. Towards a Smart City Platform Intelligence: PI Decoupling Mathematical Model for Temperature and Humidity Control was investigated by Altayeva [20]. Multi-variable greenhouse control using the decoupling method of feedback linearization was investigated by Meihui [21]. Ilyas [22] studied the MIMO system PID controller using the Ant Colony Algorithm and its application to the cage system. Test and Analysis of the Degradation Induction Potential of Silicon PV Crystal Modules was investigated by [23]. Relative humidity control in agricultural 
greenhouses was investigated by Labidi [24]. The design of a wireless mobile environmental monitoring system based on a round amphibious robot was investigated by Guo [25]. Polyhouse automation using PLC was investigated by Risodkar [26].

The reason for the need and importance of the availability of baby incubators is the background for the design of baby incubators that can automatically regulate or control the temperature and humidity of baby incubators. The incubator that is designed can automatically turn on the heating element if the incubator temperature is below normal limits and turn on the fan if the incubator temperature is above normal limits..

\section{METHOD}

The baby incubator designed was $60 \times 40 \times 30 \mathrm{~cm} 3$. The material for this incubator was made of acrylic material and divided into two parts. The lower part was used to put electronic components and the upper part was used to place a baby. Holes were made on the right and left side of the for the air circulation.

\section{A. System block diagram}

The design of this baby incubator utilizes DHT11 temperature and humidity sensors as well as the DT-AVR Low Cost Micro System microcontroller [27]-[30]. The output of the DHT11 sensor is in the form of a digital signal so it does not need analog to digital conversion (Analog to Digital Converter - ADC). The results of reading the DHT11 sensor are then sent to the LCD to display the results of measurements of temperature and humidity of the air. The LCD used is a 2x16 LCD. While the driver is used to turn on or turn off the fan and heater. Heaters are used to maintain the temperature of the incubator within the limit of $33-35^{\circ} \mathrm{C}$. The fan is used to adjust the temperature incubator humidity. The hardware design block diagram is shown in Figure 1.

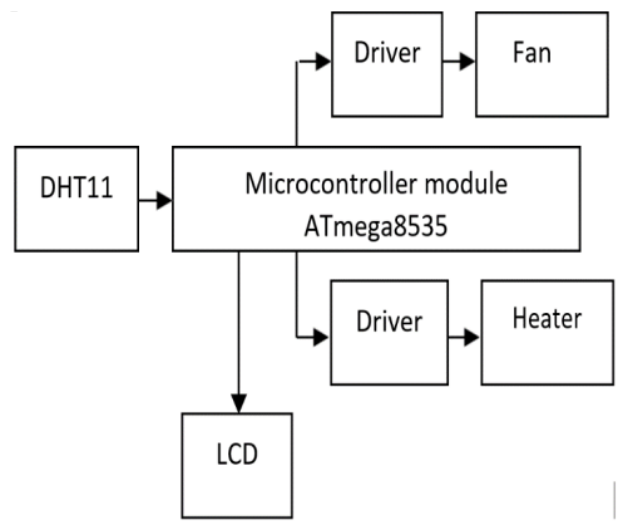

Fig. 1. System block diagram

\section{B. Sensor DHT11}

DHT11 sensor is a sensor that measures the humidity and temperature of the surrounding air. DHT11 sensor output in the form of a calibrated digital signal. The temperature measurement range of this sensor is $0-50{ }^{\circ} \mathrm{C}$ and the relative humidity measurement range is $20-90 \%$. The DHT11 sensor requires a power supply of 3 to 5.5 Volt DC. The accuracy for the relative humidity is $\pm 4 \%$ and the accuracy for the temperature is $\pm 2^{\circ} \mathrm{C}$. In the DHT11 temperature and humidity sensor, the measured humidity value is relative humidity. Relative humidity $(\mathrm{RH})$ can be defined as the ratio of the partial pressure of water vapor to saturation pressure (saturation) of water vapor, usually expressed in percent. Relative humidity is a measure of the degree of air saturation.

Free air will always contain water vapor. If the air contains all the water vapor it can carry, it is said that the air is saturated. At low temperatures, very little moisture is needed to saturate the air. While at high temperatures, it takes a lot of water vapor to make the air saturated. So, if suddenly the air temperature drops, some of the water vapor will condense. Air is not always in a saturated condition but in general is in a state below the saturation point. If the relative humidity is $100 \%$, this means that the air is saturated or saturated. Saturation means that the air is full of water vapor. Meanwhile, if the relative humidity is $0 \%$, it means that the air is complete.

\section{Microcontroller ATMega8535}

ATmega8535 has 40 pins. The ATmega8535 microcontroller has 32 main features including 32 input / output ( $/$ / O) channels, namely port $\mathrm{A}$, port $\mathrm{B}$, port $\mathrm{C}$, and port $\mathrm{D}$ and 10-bit Analog to Digital Converter (ADC) as many as 8 channels. The minimum circuit of ATmega8535 microcontroller with $16 \mathrm{MHz}$ oscillation frequency is shown in Figure 2.

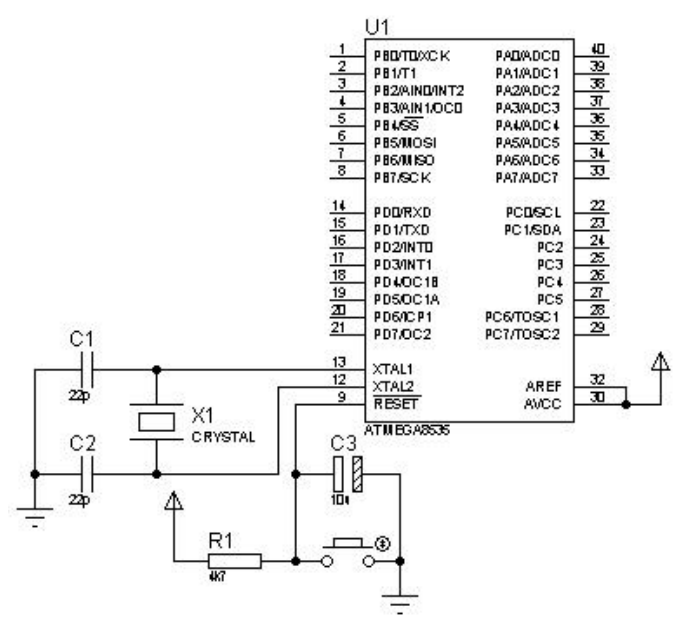

Fig. 2. ATMega8535 system minimum schematic.

Fan activator and heater circuitThe fan and heating element are activated by a 12 Volt relay based on the output from the microcontroller port. The transistor functions as a switch to turn on or turn off a 12 Volt DC relay that is connected to a fan or heater. The relay for the fan is connected to the Port D0 microcontroller. The fan drive circuit is shown in Figure 3.

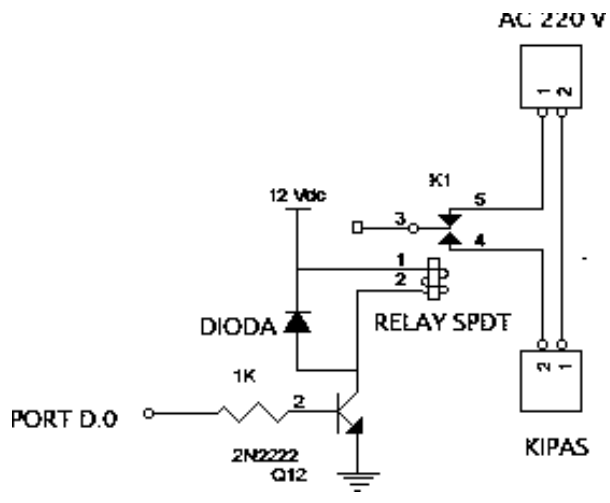

Fig. 3. Fan activator circuit schematic diagram. 
The relay for the heater is connected to the Port D1 microcontroller. The heater drive circuit is shown in Figure 4. Transistors can be used as a scalar. This means that the transistor can be operated in one of the states, namely the saturation state or the cutoff state but not in places along the load line. If the transistor is in saturation, the transistor will be like a switch that is closed from the collector to the emitter. Meanwhile, if the transistor is cutoff, the transistor will be like an open switch.

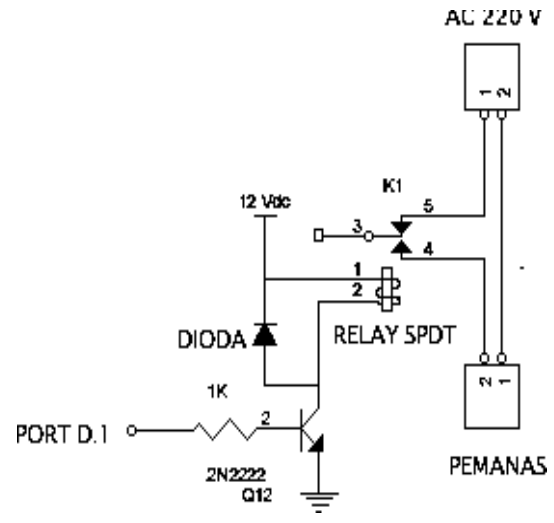

Fig. 4. Heater circuit schematic diagram.

When the input pin is logic high, the transistor is in a saturation state so that it will produce a VCE voltage of 0.2 volts or close to 0 volts so that the relay can work on a fan or heater. Conversely, if the input pin is logic it makes the transistor work in a cut-off condition. In the cut-off condition the VCE voltage will be almost the same as VCC so the relay does not work to turn on the fan or heater.

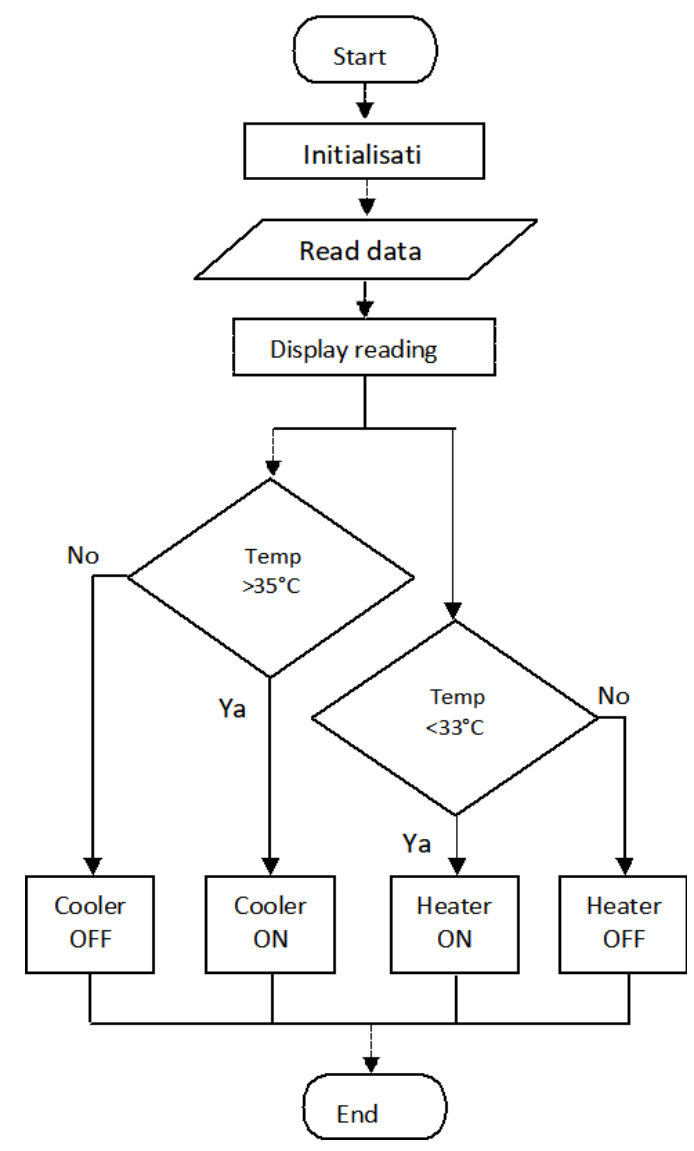

Fig. 5. Program flow chart.

\section{Microcontroller program}

This system program contains commands to read data from the sensor and display it on the LCD. It also contains a setup command to turn on and turn off the heater and fan according to the flowchart in Figure 5. First it starts with the initialization and declaration of variables. In addition there are also initial ports used for sensor communication to the microcontroller and for microcontroller communication to the relay, and LCD configuration. Then proceed with the command to retrieve data from the DHT11 sensor. After the temperature and humidity data has been obtained, it is followed by a command to display it on the LCD screen.

\section{IMPLEMENTATION}

The temperature setting is adjusted to the incubator's normal temperature limit of $33{ }^{\circ} \mathrm{C}$ to $35^{\circ} \mathrm{C}$ and uses a heater to raise the temperature in the incubator. Whereas the humidity settings are adjusted to the normal limits of the incubator's humidity at around $40 \%$ to $60 \%$ and use a fan to reduce the humidity in the incubator. The overall system test results are shown in Table 1. Based on the results of the incubator system test in Table 1, it appears that the system can work well to regulate temperature and humidity within normal limits.

TABLE I. OVERALL SYSTEM PERFORMANCE TEST

\begin{tabular}{|c|c|c|c|c|}
\hline No & $\begin{array}{c}\text { Temperat } \\
\text { ure } \\
\left({ }^{\circ} \mathrm{C}\right)\end{array}$ & $\begin{array}{c}\text { RH } \\
(\%)\end{array}$ & Heater status & Fan status \\
\hline 1 & 31 & 45 & ON & OFF \\
\hline 2 & 31 & 46 & ON & OFF \\
\hline 3 & 32 & 44 & ON & OFF \\
\hline 4 & 34 & 43 & ON & OFF \\
\hline 5 & 35 & 43 & OFF & OFF \\
\hline 6 & 33 & 55 & ON & OFF \\
\hline 7 & 35 & 53 & OFF & OFF \\
\hline 8 & 35 & 52 & OFF & OFF \\
\hline 9 & 35 & 53 & OFF & OFF \\
\hline 10 & 35 & 55 & OFF & OFF \\
\hline
\end{tabular}

When the temperature reaches $35^{\circ} \mathrm{C}$, the heater turns off and will turn on again if the temperature is below $33^{\circ} \mathrm{C}$. When the incubator humidity is above $60 \%$, the fan will turn on until the incubator humidity reaches $40 \%$. When the incubator's humidity has reached $40 \%$, the fan will turn off. The fan will turn on again if the humidity returns to above $60 \%$.

\section{CONCLUSION}

Based on the design of the baby incubator made, it can be concluded that this baby incubator can work well according to the incubator's normal temperature limit. If the temperature is below the normal range, the heating element will ignite until the lower limit of the incubator temperature is reached. The baby incubator that is designed is still in the stage of development and refinement to get better performance. Great hope, this incubator will also be very useful later for those who need baby incubator facilities. 


\section{REFERENCES}

[1] D. Gao, "Design and Implementation of Intelligent Control System for Green Building," in 2019 11th International Conference on Measuring Technology and Mechatronics Automation (ICMTMA), 2019, pp. 2831.

[2] S. A. Ili Flores, H. J. Konno, A. M. Massafra, and L. Schiaffino, "Simultaneous Humidity and Temperature Fuzzy Logic Control in Neonatal Incubators," in 2018 Argentine Conference on Automatic Control (AADECA), 2018, pp. 1-6.

[3] A. A. N. Azlin, H. Mansor, A. Z. Hashim, and T. S. Gunawan, "Development of modular smart farm system," in 2017 IEEE 4th International Conference on Smart Instrumentation, Measurement and Application (ICSIMA), 2017, vol. 2017-Novem, no. November, pp. 16.

[4] Z. Peng, "PID Control of Temperature and Humidity in Granary Based on Improved Genetic Algorithm," in 2019 IEEE International Conference on Power, Intelligent Computing and Systems (ICPICS), 2019, pp. 428-432.

[5] M. Li, J. Wei, and T. Shen, "Temperature and humidity decoupling control for enthalpy difference Laboratory," in 2018 Chinese Automation Congress (CAC), 2018, pp. 1174-1178.

[6] F. Gouadria, L. Sbita, and N. Sigrimis, "Comparison between selftuning fuzzy PID and classic PID controllers for greenhouse system," in 2017 International Conference on Green Energy Conversion Systems (GECS), 2017, pp. 1-6.

[7] B. Qin, X. Wang, L. Wang, H. Zhao, X. Yin, and L. Jia, "Hydrogen Excess Ratio Control of Ejector-based Hydrogen Recirculation PEM Fuel Cell System," in 2019 34rd Youth Academic Annual Conference of Chinese Association of Automation (YAC), 2019, pp. 648-653.

[8] Q. Wu, W. Cai, and S. Shen, “An energy efficiency control strategy for a building-oriented dehumidification system," in 2018 IEEE International Conference on Industrial Electronics for Sustainable Energy Systems (IESES), 2018, pp. 459-464.

[9] D. Wicaksono, E. Firmansyah, and H. A. Nugroho, "A microclimate closed house control design for broiler strain," in 2017 7th International Annual Engineering Seminar (InAES), 2017, pp. 1-6.

[10] H. Zheng, X. Wang, X. Chu, and Y. Zhou, "Intelligent Systems of Climate Chamber for Water Supply Based on Feedforward PID," in 2019 IEEE 6th International Conference on Industrial Engineering and Applications (ICIEA), 2019, pp. 819-823.

[11] Z. Yao, J. Li, X. Zheng, and X. Zheng, "Experiments of Cryogenic Dew and Frost Point Hygrometer for Upper Air Sounding," in IGARSS 2018 - 2018 IEEE International Geoscience and Remote Sensing Symposium, 2018, pp. 3123-3126.

[12] M. Heidari and H. Khodadadi, "Climate control of an agricultural greenhouse by using fuzzy logic self-tuning PID approach," in 2017 23rd International Conference on Automation and Computing (ICAC), 2017, no. September, pp. 1-6.

[13] X. Shuang, Z. Dongyang, L. Zhen, and Z. Hui, “A Combined Control Method of Temperature and Humidity Inside the Museum Cabinet," in 2019 11th International Conference on Measuring Technology and Mechatronics Automation (ICMTMA), 2019, pp. 322-326.

[14] H. Wu, "Design and Implementation of a Constant Humidity Control System," in 2018 3rd International Conference on Mechanical, Control and Computer Engineering (ICMCCE), 2018, pp. 192-195.

[15] B. Ban and S. Kim, "Control of nonlinear, complex and black-boxed greenhouse system with reinforcement learning," in 2017 International Conference on Information and Communication Technology Convergence (ICTC), 2017, vol. 2017-Decem, pp. 913-918.
[16] J. Tu, B. Liu, and H. Wang, "The Multiple parameters double fuzzy decoupling PID algorithm for pig breeding system," in 2019 6th International Conference on Systems and Informatics (ICSAI), 2019, no. Icsai, pp. 649-654.

[17] W. Mama and T. Radpukdee, "Development of a PID Control Law for an ON/OFF Actuator with Operating Signal Saturation," in $201821 \mathrm{st}$ International Symposium on Wireless Personal Multimedia Communications (WPMC), 2018, vol. 2018-Novem, pp. 230-235.

[18] A. A. P. Figueroa, J. J. M. Silupu, and R. S. Garcia Zabaleta, “Adaptive PID controller with auto-tuning applied to the agricultural food industry," in 2017 CHILEAN Conference on Electrical, Electronics Engineering, Information and Communication Technologies (CHILECON), 2017, vol. 2017-Janua, pp. 1-7.

[19] Izhar, W. Xu, X. Wang, R. Wang, and Y.-K. Lee, "Low-Cost Micro Predictive Mean Vote (PMV) Sensor and its Application for Smart Personal Ventilation Systems," in 2019 IEEE 32nd International Conference on Micro Electro Mechanical Systems (MEMS), 2019, vol. 2019-Janua, no. January, pp. 841-844.

[20] A. Altayeva, B. Omarov, and Y. I. Cho, "Towards Smart City Platform Intelligence: PI Decoupling Math Model for Temperature and Humidity Control," in 2018 IEEE International Conference on Big Data and Smart Computing (BigComp), 2018, pp. 693-696.

[21] L. Meihui, D. Shangfeng, C. Lijun, and H. Yaofeng, "Greenhouse multi-variables control by using feedback linearization decoupling method," in 2017 Chinese Automation Congress (CAC), 2017, vol. 2017-Janua, no. x, pp. 604-608.

[22] L. Ilyas, E. Ahmed, and S. Nacer, "PID Controller of a MIMO system using Ant Colony Algorithm and its application to a poultry house system," in 2019 5th International Conference on Optimization and Applications (ICOA), 2019, pp. 1-7.

[23] F. Jiang, H. Liu, and X. Zou, "Test and Analysis of Potential Induced Degradation in Crystalline Silicon PV Modules," in 2018 Chinese Control And Decision Conference (CCDC), 2018, pp. 4993-4996.

[24] A. Labidi, A. Chouchaine, and A. K. Mami, "Control of relative humidity inside an agricultural greenhouse," in 2017 18th International Conference on Sciences and Techniques of Automatic Control and Computer Engineering (STA), 2017, vol. 2018-Janua, no. 1, pp. 109114.

[25] S. Guo, X. Yang, J. Guo, and C. Li, "Design of Wireless Mobile Environment Monitoring System Based on Spherical Amphibious Robots," in 2018 IEEE International Conference on Mechatronics and Automation (ICMA), 2018, pp. 960-965.

[26] Y. R. Risodkar and D. V. Ugale, "Polyhouse Automation Using PLC," in 2018 International Conference On Advances in Communication and Computing Technology (ICACCT), 2018, pp. 548-552.

[27] A. Latif, H. A. Widodo, R. Rahim, and K. Kunal, "Implementation of Line Follower Robot based Microcontroller ATMega32A," J. Robot. Control, vol. 1, no. 3, pp. 70-74, 2020.

[28] N. H. Wijaya, F. A. Fauzi, E. T.Helmy, P. T. Nguyen, and R. A. Atmoko, "The Design of Heart Rate Detector and Body Temperature Measurement Device Using ATMega16," J. Robot. Control, vol. 1, no. 2, pp. 40-43, 2020.

[29] T. P. Tunggal, A. W. Apriandi, J. E. Poetro, E. T.Helmy, and F. Waseel, "Prototype of Hand Dryer with Ultraviolet Light Using ATMega8," J. Robot. Control, vol. 1, no. 1, pp. 7-10, 2020.

[30] S. Widadi, Z. A. Manzila, I. Ahmad, and O. Tanane, "Aroma Electric Therapy Equipment with Atmega8 -Based Heart Rate Monitoring," J. Robot. Control, vol. 1, no. 2, pp. 49-54, 2020. 